\title{
Caring Model Process Approach in Finding the Meaning of Patient's Life a Research Critique: Development of the Theory of Nursing Engagement Model for Humanoid Nursing People and Robots (By Tetsuya Tanioka)
}

\author{
Mohamad Judha $^{1 *}$, Maria Elizabeth C. Baua ${ }^{2}$ \\ ${ }^{1}$ Departemen of Nursing Respati Universitas of Yogyakarta, Indonesia \\ ${ }^{2}$ Department of Nursing, St. Paul University Philippines
}

DOI: $10.36348 /$ sjnhc.2020.v03i09.003 $\quad$ | Received: 12.09 .2020 | Accepted: 24.09 .2020 | Published: 30.09 .2020

*Corresponding author: Mohamad Judha

\section{Abstract}

The purpose of this paper is to analyze the form of professional services in order to meet human needs, according to the paradigm trying to be replaced by artificial intelligence. Several attempts were made by experts to create a tool or robot to help human activities including helping to provide health and nursing services, but can technology replace, That nursing sees humans as a whole, it requires a professional attitude and caring with attention, while humans have hope and efforts to achieve meaning in life, especially when feeling pain, becomes a challenge in the future that one day technology is able to provide direction for patients who because of their illness experience the process of losing.

Keywords: Human needs, nursing Paradigm, humanoid robot, theory of nursing.

Copyright @ 2020: This is an open-access article distributed under the terms of the Creative Commons Attribution license which permits unrestricted use, distribution, and reproduction in any medium for non-commercial use (NonCommercial, or CC-BY-NC) provided the original author and source are credited.

\section{INTRODUCTION}

Humans are open systems that are always considered by sticking with their external environment and always trying to balance their internal conditions (homeoatatis). Humans have a mind, feelings, body and soul unity, are able to adapt and are a unitary system that is mutually A, interrelated and interdependent [1]. The role of the nurse also helps families to improve their ability to solve health problems, namely as a nurse as a detector for health problems, providing care for family members who are sick, coordinating family health services, facilitators, educators and family advisors on health problems.

Paradigm provides a basis for seeing, seeing, giving meaning, responding to and choosing actions against various phenomena that exist in nursing. Nursing is a form of professional service, which is an integral part of health services based on nursing knowledge and tips, with services including biopsychosocio-spiritual that serves individuals, families, groups and communities both healthy and sick in the human life cycle [2]. In nursing there are four components which form the archetype of nursing theories or nursing paradigms. The four components include: people, nursing, environment, and health.
The development of the world of nursing cannot be separated from the Florence Nightingale concept model which places the environment as the focus of nursing care, the environment can be with technology, including a nurse being able to carry out independent nursing practice without burdening the profession of the Council of Nurses (ICN) [3, 4]. The concept of the model provides inspiration in the development of nursing practice so that in the end it develops widely, the paradigm of nurses in nursing action only provides the wrong environment, but the environment can affect the patient handling process, so it needs attention, and nursing services should also keep up with the times and technology without putting human values aside [5].

\section{CARE AND TECHNOLOGY}

In the consideration of identifying technology and its use in human health nursing [6], there are several dimensional categories, namely: 1). Technology as a human complement to reformulate the ideal human being, 2). Technology as machine technology, for example computers and gadgets, increases nursing activities to provide quality patient care, 3). Technologies that represent human and human activities to handle nursing care practices, for example cyborgs (cybernetic organisms) or robotic machines, 4). 
Technology as an enhancer of human quality is exemplified in the potential of cybernetic organisms, technology as an organic / biological version of human quality enhancer as chimeras.

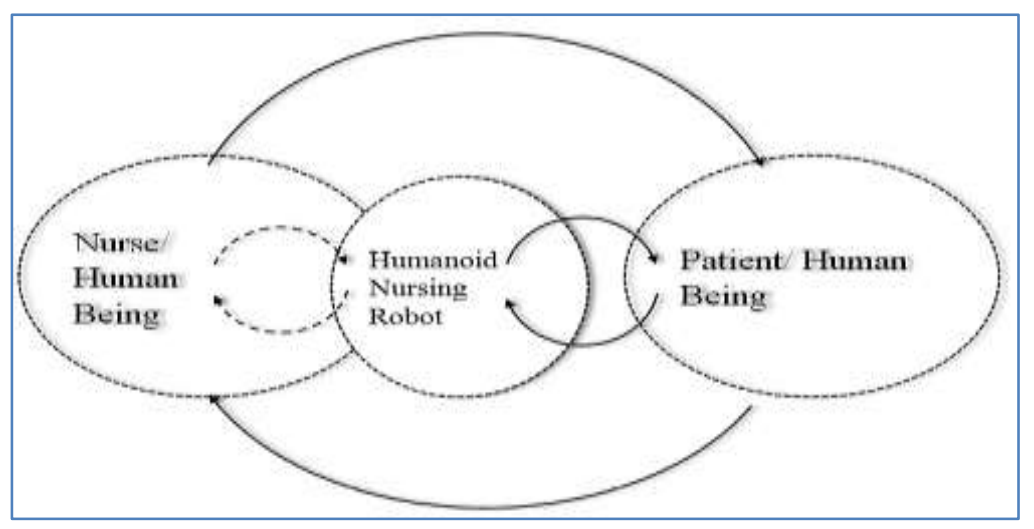

Adopted Tonika T, 2017

Nursing robotic technology at least has the ability to remember various experiences with patients; the ability to process language and maintain conversation; and to read and describe emotions. In the era of industrial revolution 5.0 in the world of nursing, it can be seen from 2 aspects, namely positive aspects and negative aspects, on the positive side, robot technology can provide drugs to patients and ease the work of nurses in several jobs [6], but robots can never care for nurses in any era. An important factor of nurse competence consistently is to provide care without reducing the essence of care. However, the most important thing that needs to be considered is that in order to function competence with this technology must be understood and appreciated as an expression of care in nursing [6]. Another thing that needs to be improved according to its development is to prioritize patient safety as care for patients. Nurses must also have critical thinking to have innovative ideas, and be adaptive to the changing times faced by all elements, both patients and other medical personnel [5].

Views regarding the replacement of human nurses with HNRs It may be inevitable that in the following situations, conditions are established that are conducive to replacing human nurses with humanoid nurse robots (HNRs), namely: 1). When nursing practice is defined as the completion of a task in which the nurse performs an efficient job with excellence dictated by precision and speed. If these characteristics mark the nurse, then the nurse can easily be replaced by HNRs. From a technological stance, health robots will perform 'nursing jobs' more precisely and efficiently. 2). When nursing is viewed as a relationship between nurse and cared for where involvement, caring between, and co-creation at this time are characteristic for uncertainty in non-theoretical practice based as an expert nurse according to Benner's [7] point of view, demands for superintelligence beyond today's human expectations are very important. Nursing practice as human-tohuman and as human-to-human-like relationships can now be revisited and reviewed, both for nurses and cared for humans with technology-enhanced constituencies, and / or can partially consist of biomechanical parts through organ replacement. Artificial or organic transplants.

Whether technology can help patients from the psychological side, or whether technology can find meaning in life according to chronic disease sufferers. The meaning of life according to Reker [8] is the values that are important and very meaningful for a person's personal life which functions as a life goal that must be fulfilled and as a guide in activities. If something happens or happens to someone, then someone who has a positive meaning in life will help increase his awareness of unwanted circumstances. The same thing was expressed by Wiebe [9] that meaningfulness in life is related to high self-esteem and generous behavior towards others, while meaninglessness in life is related to ignorance or detachment.

According to Judha and Deden [10], the meaning of life is something that is valuable and gives a special value to someone; the meaning of life if found and fulfilled will make life feel so valuable. Thus it can be said that happiness is a reward or side effect of someone who is able to fulfill the meaning of life.

The special characteristics of the meaning of life according to Bastaman [11] include: (1) The meaning of life is unique, personal and temporary. This means that everything that approaches someone does not necessarily mean to others and can change over time. (2) Real and specific, the meaning of life from one's experiences and everyday life from the past. (3) Can provide direction and direction, the meaning of life that a person finds will provide direction and direction for activities carried out so that the meaning of life seems to challenge and invite someone to fulfill.

According to Frankl [12], it explains that meaning can be obtained in three ways, namely, (1) Creative value, an activity obtained from looking for 
the potential that exists in oneself, others and from their beliefs. (2) The value of appreciation is a feeling obtained from a sense of acceptance of all events that occur in his life. (3) The value of existence is the ability to accept and determine the things that happen appropriately.

According to Bastaman [12], there are components that can be used to solve problems and develop a life that has stopped. These components are categorized into three dimensions, namely (1) the personal dimension, namely increasing awareness of the current poor condition of society and a strong desire to make changes for the better. (2) The social dimension is social support, namely the presence of a number of people who cannot be trusted and are willing to provide assistance. (3) The value dimension, includes dimensions, meaning of life, important values and is very close to one's personal life, which functions as a life goal that must be fulfilled and leads to activity, selfcommitment.

Furthermore, the health care environment will depend on dynamic social developments in which technologies such as the environment are used to make people healthy and prosperous. Therefore, the final focus of nursing expression in care is health and wellbeing where nurses improve the standard of living of the people they care for [6].

If studied in depth, can technology replace and fulfill all of these related to the concept of basic needs, in basic needs that basic needs are actually the will, abilities, attitudes, traits and behaviors that are unique to humans, namely the characteristics inherent in human existence [7]. The success of developing the life involved is done by realizing and actualizing the potential that exists in humans [13].

\section{REFFERENCE}

1. Kozier, B. (2008). Fundamentals of nursing: concepts process and practice. pearson education.

2. Judha, M., Elly, N., Imami, N. (2010). Search for the Meaning of Life of a Client Diagnosed with Systemic Lupus Erythematosus by the Maslow and Henderson Perspectives. Indonesian Nursing
Journal, University of Indonesia. Jakarta. http://jki.ui.ac.id/index.php/jki/article/view/245

3. International Council of Nurses (ICN). (2002). ICN definition of nursing. [Accessed May 2020]. https://www.icn.ch/nursing-policy/nursingdefinitions

4. Bryant, R. (2005). Regulation, roles and competency development. International Council of Nurses.

5. Heller, B. R., Oros, M. T., \& Durney-Crowley, J. (2000). 10 TRENDS to Watch. Nursing and Health Care Perspectives, 21(1), 9-9.

6. Tanioka, T. (2017). The development of the transactive relationship theory of nursing (TRETON): a nursing engagement model for persons and humanoid nursing robots. International Journal of Nursing \& Clinical Practices, 2017.

7. Potter, P.A \& Perry, A.G. (2017). Fundamental nursing textbooks: Concepts, processes and practices. (Issue 10). Elsevier

8. Reker, G. T., \& Chamberlain, K. (2000). Exploring Existential Meaning: Optimizing Human Development Across the Life Span. California: Sage Publication. https://sk.sagepub.com/books/exploring-existentialmeaning

9. Wiebe, R.L. (2001). The influence of personal meaning on vicarious traumatization in the therapists. [Electronic version]. Accessed 27 March 2020.

https://www.twu.ca/sites/default/files/wieberonda_ 0.pdf

10. Judha, M., \& Deden, I. S. (2015). What and how is lupus (systemic lupus erythematosus). Yogyakarta Publisher: Gosyen Publishing.

11. Bastaman, H.D. (1996). Achieve a meaningful life; Personal story with a tragic experience. Jakarta; Paramadina.

12. Witte, J. S., Longnecker, M. P., Bird, C. L., Lee, E. R., Frankl, H. D., \& Haile, R. W. (1996). Relation of vegetable, fruit, and grain consumption to colorectal adenomatous polyps. American Journal of Epidemiology, 144(11), 1015-1025.

13. American Psychological Association. (2008). Classification of need. https://www.apa.org/ed/precollege/topss/lessons/e motion-1-2 accessed June 22, 2020. 